\title{
Knowledge management strategy and organizational change in commercial banks in Kenya
}

\author{
Jackson K. Maalua* PhD, Said Mwachinalo Dosho ${ }^{\text {b }}$ \\ a Mombasa Campus, University of Nairobi \\ ${ }^{b}$ Research Scholar, Mombasa Campus, University of Nairobi \\ *Corresponding author's email: jmaalu@uonbiac.ke
}

\section{A R T I C L E I N F O}

Received: 15-06-2016

Accepted: 10-07-2016

Available online: 21-07-2016

\section{Keywords:}

knowledge management, strategy, organizational change,

commercial banks

JEL Classification:

\begin{abstract}
A B S T R A C T
This study attempts to establish the relationship between knowledge management strategy and organizational change in commercial banks in Kenya. Knowledge management strategy can assist a firm to induce individuals to offer their knowledge voluntarily for a firm's use, achieve distinctive advantage through full exploitation of a firm's knowledge base, build institutional memory and protect it from prying competitors. It can influence amongst others a successful organizational change. The study employed a descriptive cross sectional survey. A total of 39 commercial banks in operation (not under statutory management) were surveyed. Primary data was collected from the respondents using a questionnaire. Analysis utilized largely the median and mode as measures of central tendency while the inter-quartile range was used as a measure of dispersion. Percentages and frequencies were also utilised to present part of the findings. Pseudo R square statistics were used as a measure of association between knowledge management strategy (independent variable) and organizational change (dependent variable). The study found that commercial banks in Kenya primarily employ proactive and moderate knowledge management strategies. Both strategies had a strong association with the organizational changes that the commercial banks have undergone. The most popular form of organizational change was found to be a mix of both revolutionary and evolutionary change. The findings of this study are consistent with theory in that knowledge management strategy was found to have given banks dynamic capabilities in pursuit of a firm's goals such as organizational change.
\end{abstract}

This is an open access article under the terms of the Creative Commons Attribution License 4.0, which allows use, distribution and reproduction in any medium, provided the original work is properly cited.

DOI: http://dx.doi.org/10.18533/rss.v1i7.44

ISSN: 2378-8569 (Print), 2378- 8550 (Online)

\subsection{Introduction}

In the contemporary society, the ability to generate and exploit knowledge is of critical importance for the competitiveness of any organization (Drucker, 1993). A knowledge management strategy is thus important in providing a codified means of effecting organizational change congruent with its mission (Beckett, Wainwright \& Banes, 2000). A knowledge management strategy generates a repository upon which organizations can extract value from processes scheduled across times hence build its capacity for change (du Plessis, 2007).

The commercial bank sector has been marked with high levels of innovations and competition as a result of globalization. The implication of this means that commercial banks have had to change in order to remain 
competitive in a rapidly changing environment. Indeed part of the imposed change on some of the traditional banks has seen them have an increased uptake of technology to challenge the online banking trend (Joseph et al., 2003). Mechanisms for developing and managing knowledge bases are therefore critical in the sector to ensure continued innovation and competitiveness (Corno et al., 1999).

The concept of knowledge management strategy and organizational change has not received much attention. Knowledge management strategy is itself a contemporary issue that is yet to be studied exhaustively. The world today is marked with rapid changes that require a fluid knowledge management strategy to minimize negative impact on firms and ensure achievement of organizational goals. It is therefore important to understand the influence of knowledge management strategy on various actions taken by organizations such as change.

Commercial banks in Kenya have over time changed in response to rapidly changing; technologies, customer preferences and forms of competitors. The study of the relationship between knowledge management strategy and organizational changes is thus important to commercial banks. This is especially so because appropriate application of knowledge management strategy may enhance the competitiveness of a bank. More so, organizational change occur at a cost.

A review of previous studies done indicate that most concentrated on; knowledge management and business process reengineering, knowledge management and innovation, implementation of knowledge management and the influence of knowledge management on performance. Greiner, Bohmann and Krcmar (2007)carried out a study on the linkage of knowledge management strategies to business strategies. The key finding was that alignment of knowledge management strategy and business strategy is important for organizations to perform. Olouikpe (2012) studied the importance of linking knowledge management strategy to business strategy and thus performance. He concluded that proper alignment results to both efficiencies and effectiveness. Maseki (2012)studied the linkage of the banks' performance with their knowledge management practices. The researcher found that knowledge management was related to bank's performance. Muthee (2014)sought to find out how Safaricom employed knowledge management as a strategic tool in its pursuit for competitive advantage. He found that knowledge management can minimize uncertainties associated with a volatile environment and that it could enhance competitiveness. A review of previous studies done indicate that most concentrated on; knowledge management and business process reengineering, knowledge management and innovation, implementation of knowledge management and the influence of knowledge management on performance. Consequently, Massingham (2014) suggested that studies need to be carried out to examine amongst others the linkage of knowledge management strategy and organizational change and performance. This study aimed to address this knowledge gap by answering the following research question; to what extent is the relationship between knowledge management strategy and organizational changes among Commercial Banks in Kenya?

The study had three objectives. The first objective was to identify the knowledge management strategy used by Commercial Banks in Kenya. The second objective was to establish the types of organizational change that have taken place in Commercial Banks in Kenya. The last objective was to determine the relationship between knowledge management strategy and organizational changes among Commercial Banks in Kenya.

To achieve the study objectives, a cross sectional descriptive survey was carried out. A census study of 39 Commercial banks in operation was conducted. Likert type questionnaire was used to collect ordinal data from the heads of strategy and new businesses in the respondents' banks. The study found that commercial banks in Kenya employ primarily two knowledge management strategies viz; proactive and moderate strategies. Both strategies were found to have a strong association with organizational changes that the commercial banks have undergone. Commercial banks were also found to have employed a mix of revolutionary and evolutionary organizational change.

The study contributes to the existing literature on knowledge management strategy by validating its importance in building up a firm's dynamic capabilities. It also validates the existing theories on importance of knowledge in establishing distinctive competencies. The study shows how an integrative and comprehensive knowledge management strategy significantly influences important firm's goals such as organizational change. The findings suggest for the need of a policy that tries to fully exploit the dimensions of a comprehensive knowledge management strategy viz; the breadth of the concept knowledge management, knowledge management tools and support mechanisms to facilitate the achievement of organizational goals.

This paper is organized as follows: section 1, introduction; section 2, literature review; section 3, methodology; section 4, findings; section 5, discussion of findings; section 6, policy implications and study recommendations and finally, conclusion in section 7 . 


\subsection{Literature Review}

The concept studied is based on the; resource based theory, competence based theory and the knowledge based theory. The resource based theory acknowledges that a firm's resource can enable it develop strategic competencies (Sanchez and Heene, 2005). Indeed the determination of what constitutes resources in an organization depends on knowledge (Foss et al., 2007). Therefore an organization can be explained as a set of interrelated elements based on knowledge (Tsoukas, 1996).

Barney (1991) argues that a firm's resources can only confer it with an edge over its competitors if it provides sustained incremental value over time in its competitiveness relative to its competitors. A knowledge management strategy provides this competitive edge through leveraging the knowledge assets. A knowledge management strategy is able to mediate the disequilibrium between supply and demand conditions that may turn a valuable resource into a liability (Knott, 2009) through providing a consistent and coherent way of navigating through such disequilibrium.

Knowledge based theory places premium on the abilities of knowledge to help organizations to change in tandem with the changes in its environment by altering its competencies (Bareto, 2010). Knowledge is the most important asset that if well harnessed can enable an organization achieve its long term objectives and goals plus confer it with a competitive advantage (Zack, 1996). It follows therefore that knowledge should form the fulcrum upon which the activities of an organization revolve around.

The actions and inactions that organizations undertake are based on the knowledge in its possession. Knowledge helps an organization makes sense of the uncertainties of the environment. It does this by providing an interpretation of such uncertainty to a given a reality that motivates its actions and change abilities (Sveiby, 1994). Thus it can be argued that knowledge informs organizational change be it evolutionary or revolutionary. Knowledge however on its own without some sort of coherent application may not provide the value it possesses. A mechanism should be devised that can enable the knowledge in an organization be shared through a network (Seufert et al., 1999).

Competence based theory sees the dynamism of an organization as based on the tacit knowledge and skills that its personnel possess and the way it's coordinated (Hodgson, 1998). Knowledge as being one of the competencies of the organization can be used for adaptation through responding to the environment it operates hence allow it deliver on its potential (March, 1991). The competence theory asserts that it's the managers' decision making that matters. It holds that managers' rationality in decision making is relative contingent upon the respective organization's wealth of knowledge and its subsequent exploitation (Freilings, 2004). This means that managers facing similar environment will make different decisions as to the deployment of their assets as informed by the knowledge they have.

Accordingly, it is not resources that provide the competitive edge but the proficiencies shaped by organizational knowledge that is asymmetrical that does (Freilings, 2004). This theory provides a clear basis for the application of a knowledge management strategy that can help shape organization change and its performance. Knowledge shapes competencies while knowledge management strategy provides a systematic, coherent and integrative application approach.

Scholars have not been unanimous on the typologies of knowledge management strategies. Various strategies have been suggested. This study sought to relate the typologies of knowledge management strategies as suggested by Donate and Canales (2012) to organizational change among commercial banks in Kenya. Donate and Canales (2012) knowledge strategy typologies (inconsistent, passive, moderate and proactive) are based on wider dimensions that consist of the breadth of the concept of knowledge management and consistency between knowledge management tools and support mechanisms.

Donate and Canales (2012) states that knowledge management concept measures the significance attached to knowledge management in contributing to organizational goals. Knowledge management involves; exploration, retention, exploitation, sharing and safeguarding of knowledge in pursuit of organizational objectives. Knowledge strategy objectives measures the importance attached to knowledge management strategy in addressing organization's performance gaps. The gaps include those of; quality, costs, customer satisfaction, efficiency amongst others. The knowledge management concept and knowledge strategy objectives inform the breadth of the concept of knowledge management.

Donate and Canales (2012) further explains that the knowledge management tools dimension include; storage, distribution and protection. Databases, handbooks and data warehousing are some of the mediums that can be used for knowledge storage. Knowledge distribution application involves; the setting up of accessible data bases, 
the holding of meetings and seminars to share knowledge, the development of learning modules to facilitate the dispersion of new knowledge amongst others. Knowledge protection refers to deliberate efforts by an organization to protect its knowledge from external and internal parties. The use of; patents, exclusive distribution channels, secrecy, complex innovations, superior brands amongst others are meant to ensure competitors do not make any head way.

Donate and Canales (2012) aver that the implementation support mechanisms include; leadership, culture and human resources practices. Leadership through communication of a clear vision shapes the language of an organization and collective efforts towards that vision. Leadership that allows for errors to be made encourages experimentation of new ideas which breeds new knowledge. Culture shapes the beliefs and values that an organization holds. A culture that is supportive can assist in making an effective knowledge management strategy. Human resources practices such as; incentives, promotion of team work, job rotation, training and empowerment can be used in knowledge management. Proactive strategy attaches high importance to implementation support mechanisms.

The knowledge management strategy an organization adopts depends on the sensitivities of the environment (Greiner, Bohmann, and Krcmar, 2007). Organizations will adopt knowledge management strategies that reflect; competition intensity, product lifecycles, rate of changes in production processes amongst others (Picot, 1998). The exploration, storage, sharing and exploitation of knowledge in an organization is a delicate affair that is fraught with risks and therefore may be an expensive affair if not well managed (Soliman and Spooner, 2000). This means therefore that the process of knowledge management must be guided by a strategy to mitigate against such risks. This is of more importance given the turbulent environment we are in.

Malhotra (2000) emphasizes this fact when he observed that the contemporary environment has placed enormous demands on business organizations operating within it. This has forced them to pursue revolutionary changes which require a rethinking on how knowledge management is practiced. A failure to rethink how the organization can keep up with the rapid changes in today's environment might turn past core competencies into sources of inflexibility in the present. A knowledge management strategy provides a systematic and deliberate application of knowledge in possession of an organization which allows it to create order out of disorder that all sorts of organization change may bring.

Through creation of new knowledge an organization shapes its future and through knowledge sharing the organization solidifies its present by incorporating experiences into its corporate memory. The shape the organization takes in terms of its design and the way it operates must reflect the organization's knowledge (Malhotra, 2000). This means that knowledge management strategies adopted can reflect the sort of changes an organization adopts. From the afore discussion we hypothesize thus;

\section{Hо: Knowledge management strategy is strongly related to organizational change amongst commercial banks in Kenya.}

\subsection{Methodology}

The population of interest consisted of all commercial banks in Kenya. According to the Central Bank of Kenya (2015) there were 42 licensed commercial banks operating in Kenya. However, three commercial banks were under statutory management at the time of conducting the study. The three banks under statutory management were excluded from the study as they were engaged in turnaround strategies and liquidation procedures making them inappropriate respondents. Therefore a census of only 39 banks that were operational was carried out. The census was done due to the small size of the population and the researcher's aim to increase reliability of findings in a sector where industry practises among the banks maybe different (Cooper and Schindler, 2014).

The study used primary data obtained from the respondent commercial banks. Primary data was used since the data the study sought is not documented nor available in the public domain. A modified 7 scale Likert type questionnaire adapted from Donate and Canales (2012) was used for data collection. The 7 scale Likert was used as it reduces partiality of responses from respondents and also offers highest reliability and variance (Stennet, 2002). A drop and pick later method of administering the questionnaires was adopted.

The questionnaire sought responses ranging from very low to very high and from totally disagree to totally agree on a scale of one to seven to the questions posed. To identify the type of knowledge management strategies employed by commercial banks in Kenya, the questionnaire was split into three major sections viz; knowledge strategy, knowledge management tools and implementation support systems. These three sections were further split into seven subsections namely; knowledge management conception, knowledge strategy 
objectives, storage tools, transfer and application tools, protection methods, implementation support system based on cultural principles and leadership and implementation support systems based on human resources practises.

To establish the types of organizational changes that commercial banks have undergone, the questionnaire was designed to elicit responses in the three forms of organizational change viz; radical change, incremental change and a mix of incremental and radical change. Further, the section covering radical change was subdivided into three subsections namely; reengineering, innovation and restructuring.

To identify the type of knowledge management strategies employed by commercial banks in Kenya, the mode score for each of the seven subsections making up knowledge management strategy was computed and overall mode score for each respondent commercial bank in the seven subsections determined. This overall mode score was then compared to Donate and Canales (2012) suggested model overall mode scores for the different knowledge management strategies viz; moderate strategy 5.00, inconsistent strategy 4.00, passive strategy 1.00 and proactive strategy 6.00. This comparison allowed for the identification of knowledge management strategies as employed by commercial banks. The median for each of the three sections (knowledge strategy, knowledge management tools and implementation support systems) was then used to establish the surveyed banks; scope of knowledge management concept and its alignment to knowledge management tools used and the implementation support systems utilised. The interquartile range was used to measure variation in the respondents' banks' opinion. Where there was divergence of views (inter quartile range that is equal to or greater than 2.00), percentages of how the responses were spread was presented.

To establish the types of organizational changes that commercial banks have undergone, percentages were computed to identify the most prevalent organizational change. The median score for reengineering, innovation and restructuring was then used to infer what on average the respondents practised. The inter quartile range was used to measure variance in opinion as regards common radical change practises. Where a large inter quartile range was recorded (range equal to or greater than 2.00), percentages of how the responses were spread for the affected practise were presented.

To determine the relationship between knowledge management strategy and organizational changes, ordinal regression was carried out. Knowledge management strategy was the designated independent variable and the forms of organizational change were the dependent variable. Cox and Snell, Nagelkerke and McFadden coefficients were then used to measure the association of the following variables; knowledge management strategy and reengineering, knowledge management strategy and innovation and knowledge management strategy and restructuring. To interpret the coefficients, the study used the guide as suggested by Kraska - Miller (2008). A score of 0.2 was considered as a weak relationship, 0.6 moderate association and 0.8 strong association.

\subsection{Findings}

The study targeted 39 operational Commercial Banks out of which 30 of them responded to the researcher's questionnaire. This corresponds to a response rate of $76.92 \%$. This is in tune with an excellent response rate as averred by Mugenda and Mugenda (2003)who holds that 50\% response rate meets the adequate threshold for analysis and reporting with $60 \%$ adjudged as good while a response rate equal to or above $70 \%$ is excellent.

This study sought to identify the knowledge management strategy used by commercial banks in Kenya.Table 1.0 summarizes findings of the forms of knowledge management strategies practised by commercial banks in Kenya.

\begin{tabular}{|c|c|c|c|c|c|c|}
\hline \multicolumn{7}{|c|}{ Table 1.0: Knowledge Management Strategies } \\
\hline \multicolumn{2}{|c|}{ Bank's Classification } & \multirow[b]{2}{*}{$\begin{array}{r}\text { Inconsistent } \\
\text { Strategy }\end{array}$} & \multirow[b]{2}{*}{$\begin{array}{l}\text { Passive } \\
\text { Strategy }\end{array}$} & \multirow[b]{2}{*}{ Moderate Strategy } & \multirow[b]{2}{*}{$\begin{array}{r}\text { Proactive } \\
\text { Strategy }\end{array}$} & \multirow[b]{2}{*}{ Total } \\
\hline Ownership & Size & & & & & \\
\hline \multirow{2}{*}{ Local Public } & Small & 0 & 0 & 0 & 2 & \\
\hline & Medium & 0 & 0 & 1 & 0 & \\
\hline \multirow[t]{2}{*}{ Sub Total } & & 0 & 0 & 1 & 2 & 3 \\
\hline & Small & 0 & 0 & 2 & 6 & \\
\hline \multirow[t]{2}{*}{ Local Private } & Medium & 0 & 0 & 1 & 4 & \\
\hline & Large & 0 & 0 & 1 & 3 & \\
\hline Sub Total & & 0 & 0 & 4 & 13 & 17 \\
\hline
\end{tabular}




\begin{tabular}{lllllll}
\hline & Small & 0 & 0 & 2 & 1 & \\
Foreign Owned & Medium & 0 & 0 & 1 & 4 & \\
& Large & 0 & 0 & 0 & 2 & 10 \\
Sub Total & & 0 & 0 & 3 & $\mathbf{7}$ & $\mathbf{3}$ \\
Grand Total & & 0 & 0 & $\mathbf{8}$ & $\mathbf{2 2}$ & $\mathbf{3 0}$ \\
\hline
\end{tabular}

Source: Research Data, 2016

Using the Donate and Canales (2012) mode scores as a benchmark, two knowledge management strategies clearly came out viz; proactive strategy and moderate strategy. Out of the 30 banks that responded to the questionnaires, 22 banks (73.33\%) were found to be employing proactive strategy while the remaining 8 banks (26.67\%) were found to be employing moderate strategy. No commercial bank was found to have employed inconsistent nor passive strategy at the time of the study.

The study findings clearly indicate that commercial banks in Kenya considered the concept of knowledge management at its broadest sense. This consideration was consistent with the importance the commercial banks gave to knowledge management strategy in achieving firm's goals such as cost reduction amongst others. The findings also indicate that there's consistency between knowledge management concept and knowledge management tools and the implementation support systems as practised by commercial banks in Kenya. This alignment of the three elements making knowledge management strategy resulted to the manifestation of the two strategies found. The moderate and proactive strategies require proper alignment of the three elements that determine knowledge management strategy.

The study also aimed to establish the types of organizational change that have taken place among commercial banks in Kenya. The types of organizational change for the purpose of the study were categorised into three; radical change, incremental change and a mix of radical and incremental change. Table 2.0 below highlights the nature of organizational changes amongst commercial banks in Kenya in the last 15 years.

\begin{tabular}{|c|c|c|c|c|c|}
\hline \multicolumn{6}{|c|}{ Table 2.0: Organizational Changes among Commercial Banks in Kenya } \\
\hline \multirow{5}{*}{ Valid } & & Frequency & Percent & Valid Percent & $\begin{array}{r}\text { Cumulative } \\
\text { Percent }\end{array}$ \\
\hline & Radical & 3 & 10.0 & 10.0 & 10.0 \\
\hline & Incremental & 5 & 16.7 & 16.7 & 26.7 \\
\hline & A mix & 22 & 73.3 & 73.3 & 100.0 \\
\hline & Total & 30 & 100.0 & 100.0 & \\
\hline
\end{tabular}

22 respondents out of the possible 30 intimated that they had undergone a mix of radical (revolutionary) and incremental (evolutionary) changes. This represents $73.3 \%$ of the total respondents. 5 respondents reported incremental irregular changes affecting just a few sections of the bank accounting for $16.7 \%$ of the respondents. 3 banks reported radical (revolutionary) change accounting for $10 \%$ of the total respondents. These findings are sync with common practises amongst firms. Radical change rarely happens in isolation. Organizational change that mixes radical and incremental change offers an organization more balance. It allows for smooth transition from one form of organization to another.

To establish the frequency of radical change among commercial banks, the respondents were asked to opt between the following choices; none, less than 3, between 3 to 5 and more than 5.Table 3.0describes the frequency of radical changes amongst correspondents' banks in the last 15 years.

\begin{tabular}{llrrrr}
\hline \multicolumn{5}{c}{ Table 3.0: Radical Changes among Commercial Banks in Kenya } \\
\hline & Frequency & Percent & Valid Percent & $\begin{array}{r}\text { Cumulative } \\
\text { Percent }\end{array}$ \\
\hline \multirow{6}{*}{ Valid } & 3 & 10.0 & 10.0 & 10.0 \\
& None & 11 & 36.7 & 36.7 & 46.7 \\
& Less Than three & 13 & 43.3 & 43.3 & 90.0 \\
& Between 3 and 5 & 3 & 10.0 & 10.0 & 100.0 \\
& More than 5 & 30 & 100.0 & 100.0 & \\
Total & & & &
\end{tabular}

Source: Research Data, 2016

13 respondents representing $43.3 \%$ of the total respondents reported between 3 to 5 radical changes. 11 respondents accounting for $36.7 \%$ of the total respondents reported less than 3 radical changes in their respective banks. 3 respondents representing 10\% of the total respondents reported more than 5 radical changes. While 3 respondents representing $10 \%$ of total respondents reported nil radical changes. 
The findings point to a dynamic sector. The Commercial Banking industry has undergone a number of transformations over the last 15 years. Most banks (13) have undergone 3 to 5 radical changes in a space of 15 years. This finding on the frequency of radical changes may be credited to among other factors the; rapid technological developments, changing regulations governing the commercial banking sector, rise of competition from non-traditional competitors such as the mobile telephony companies with their money transfer services and changing customers' expectations.

This study also sought to establish the relationship between knowledge management strategy and organizational change amongst Commercial Banks in Kenya. Table 4.0 summarises the pseudo $\mathrm{R}$ square coefficients for the association between knowledge management strategy and organizational change.

\begin{tabular}{|c|c|c|c|c|c|}
\hline \multicolumn{6}{|c|}{ Table 4.0: Knowledge Management Strategy and Organizational Change } \\
\hline \multirow[b]{2}{*}{ Strategy } & \multirow{2}{*}{$\begin{array}{l}\text { Element of } \\
\text { Organizational } \\
\text { Change }\end{array}$} & \multicolumn{3}{|c|}{ Pseudo R square Coefficient } & \multirow[b]{2}{*}{ P Value } \\
\hline & & $\begin{array}{r}\text { Cox and } \\
\text { Snell }\end{array}$ & Nagelkerke & McFadden & \\
\hline \multirow{3}{*}{ Proactive } & Reengineering & 0.946 & 1.00 & 1.00 & 0.000 \\
\hline & Innovation & 0.898 & 1.00 & 1.00 & 0.000 \\
\hline & Restructuring & 0.782 & 0.807 & 0.437 & 0.004 \\
\hline \multirow{3}{*}{ Moderate } & Reengineering & 0.950 & 1.00 & 1.00 & 0.001 \\
\hline & Innovation & 0.835 & 1.00 & 1.00 & 0.044 \\
\hline & Restructuring & 0.912 & 1.00 & 1.00 & 0.007 \\
\hline
\end{tabular}

22 commercial banks employed proactive knowledge management strategy. The proactive strategy explained $94.6 \%$ of the variations in reengineering practises among the 22 commercial banks according to Cox and Snell statistic. The $\mathrm{P}$ value stood at 0.000 which is less than 0.05 . This indicates that the model does not fit the data well. This could be explained by the small sample size of 22 respondents. Proactive strategy also explained $89.8 \%$ in the variation of innovation practises amongst the respondents as per the Cox and Snell coefficient. The significance value (P Value) was less than 0.05 standing at 0.000 . This again suggest that the model does not fit the data though this can be accounted to the small sample size $(n=22)$. Proactive strategy also explained $78.2 \%$ of the variation in reengineering practises as per the Cox and Snell coefficient. The P Value stood at 0.004 showing that the model does not fit the data well. This is due to the small sample size $(\mathrm{n}=22)$.

8 commercial banks practised moderate knowledge management strategy. Moderate strategy explained 95\% of the variations in reengineering practises of the commercial banks practising the strategy as per the Cox and Snell statistic. The P Value was recorded at 0.001 which is less than 0.05 hence the model does not fit the data primarily due to small sample size $(n=8)$. Moderate strategy explained $83.5 \%$ of the variations in innovation practises of commercial banks on the basis of the Cox and Snell statistic. The P Value was recorded at 0.044 which is less than 0.05 hence the model does not fit the data well which can be accounted to the small sample size $(n=8)$. The Cox and Snell statistic further showed that moderate strategy explained $91.2 \%$ of the variations in restructuring practises amongst commercial banks. The significance value stood at 0.007 which is less than 0.05 hence the model does not fit the data due to small sample size $(n=8)$.

The findings point to a strong association of knowledge management strategy and the three elements of organizational change viz; reengineering, innovation and restructuring. It can therefore be inferred that a strong relationship exists between knowledge management strategy and organizational change. This finding however may not be conclusive as only 30 respondents were under study hence the lower significance values recorded. Further, restructuring practises were found to be low amongst commercial banks hence the study findings may make more sense when related to the high innovative and reengineering practises of commercial banks.

\subsection{Discussion of findings}

This study sought to achieve three objectives. The objectives are to; identify the knowledge management strategy used by commercial banks in Kenya, establish the types of organizational change that have taken place among commercial banks in Kenya and to determine the relationship between knowledge management strategy and organizational changes among commercial banks in Kenya. Two types of knowledge management strategies were found to be practised amongst the commercial banks. These strategies were moderate and proactive knowledge management strategies. 
As regards the types of organizational changes that have occurred amongst the commercial banks in Kenya, the three forms of organizational change (radical, incremental and a mix of radical and incremental change) clearly manifested. The organizational change that encompasses radical and incremental change was found to be the most prevalent. A strong relationship was also established between knowledge management strategy and organizational change amongst the commercial banks in Kenya.

The above findings are significant. While the P values were recorded at less than 0.05 denoting that the model does not fit the data primarily due to small sample size $(n=30)$, the findings show how an integrative and comprehensive knowledge management strategy impacts on important goals such as organizational change. The strong association between knowledge management strategy and the various aspects of organizational change means that the creation of a knowledge management strategy with an optimal balance of its elements (knowledge strategy, knowledge management tools and implementation support systems) is crucial in enabling a firm obtain dynamic capabilities (Schiuma, 2012). These dynamic capabilities have allowed the banks to change in line with the ever changing operating environment they operate in. The fluid and uncertain environment the commercial banks have been operating in has seen among others; changes in regulations governing the sector, rapid technological developments and the coming up of non-traditional competitors. The dynamic capabilities obtained through the use of optimal knowledge management strategies has enabled the banks keep abreast with the dynamism of their operating environment. Organizational change is just but one measure of coping with changes in the environment.

The strong association between knowledge management strategy and organizational change can thus be interpreted to mean that a good knowledge management strategy confers to an organization dynamic capabilities.

A narrowly defined strategy that does not reflect the organization's customs, norms and value may not yield any utility. A strategy that is not supported by human resource practices and backed by cultural principles and leadership may not translate the organizational knowledge into novel products that are profitable. This is important in building the theory concerning knowledge management strategy constructs. The use of knowledge management strategy which enables the control of the knowledge management process can assist in creating competences that are hard to replicate due to use of protection tools such as patents amongst others (Gold et al., 2001; Felin and Hesterly, 2007). It can be argued that the apt use of knowledge management strategy by Commercial Bank of Africa helped it together with Safaricom (a mobile telephony company) create M Shwari which is a product that has bestowed competencies to the bank that are hard to replicate primarily due to protection tools covering it. M Shwari was developed in November 2012 by Commercial Bank of Africa in collaboration with Safaricom which is essentially a bank account that uses the mobile money transfer platform (Consultative Group to Assist the Poor, n.d.). This was a pioneering product that has enabled Commercial Bank of Africa obtain more than 10 million saving accounts while also enabling it to process over 50,000 loans daily (Consultative Group to Assist the Poor, n.d.).

The first mover advantage coupled with other protection mechanisms saw the other players in the commercial banking sector try to cope with this proposition with difficulty. A rival could only manage to come up with a competing product in 2015 dubbed KCB M Pesa account.

This study found that on average commercial banks have undergone 3 to 5 radical changes in the last 15 years. This is fundamental as radical change tend to affect the building blocks of an institution. It affects amongst others the; structures, systems, staff and shared values and norms. A radical change that is not well managed can result to loss of organizational memory. Organizational memory can be defined as a set of tools and instruments that allow the collection, access and utilization of knowledge and experiences that an organization has accumulated over time (Olivera, 2000). Organizational memory can be eroded especially since people remain the primary source of knowledge and yet they get impacted by radical change through measures such as rightsizing. Scalzo (2006) saw the importance of proper knowledge management process in preserving institutional memory. The strong association between knowledge management strategy and organizational change validates this importance. The findings of this study contribute to theory by showing how knowledge management strategy can enable a successful radical change without the affected organization losing its competence through the erosion of institutional memory.

This study found that commercial banks rated their innovative patterns at high (median $=6.00)$. As a matter of fact, the modal score for the majority of the innovative measures was rated at 7.00 (very high) by majority of the respondents. Corno et al (1999) alludes to the importance of having mechanisms in place to allow for the leveraging a firm's knowledge bases to ensure its ability to pursue novelty and maintain its competitiveness. This is consistent with the study findings as the strong association between knowledge management strategy 
and innovative patterns of commercial banks in Kenya point to such a tool as alluded by Corno et al (1999). A comprehensive knowledge management strategy whose knowledge management concept is aligned to its knowledge management tools and implementation support systems is bound to support innovation practises. This is supported by Tsai and Ghoshal (1998) who held the view that when firms have competent knowledge distribution and creation systems they are able to be more inventive. This is consistent with the study findings.

Results of this study indicate that knowledge management strategy has a strong association to organizational change among commercial banks. The findings are consistent with theory as knowledge management strategy has been associated with innovation and reengineering. This successful organization change is a consequence of free exchange of knowledge within the firms' in question (Hamel, 1991). Moderate and proactive knowledge management strategies provide the basis for a free exchange of knowledge.

\subsection{Policy Implications and Study Recommendations}

The findings of this study are consistent with theory. Knowledge management practices including knowledge management strategy is a function of the organization's internal characteristics and the external environment in which it operates (Bierly and Daly, 2007; Haggie, 2003; Maier and Remus, 2002). Commercial banks in Kenya operate in a competitive environment marked with rivals from other industries such as the mobile telephony industry. With their resource capabilities coupled with the competition, it's no surprise that they employ proactive and moderate strategies which are consistent with innovation practises in the sector. Indeed knowledge management strategy has conferred the banks with dynamic capabilities which in turn has built up their competitive advantage. This postulation of knowledge based theory is manifested amongst the banks.

The findings suggest that policies need to be put in place to ensure knowledge management strategy is fully comprehensive. A knowledge management strategy that is not consistent with the organizational culture and leadership style is bound to fail. A culture of openness, sharing and experimenting is crucial for knowledge to proffer any competitive advantage. The leadership must ensure that human resource practises are consistent with their knowledge management strategy and knowledge management practices for any success to be found (Gloet and Berrel, 2003; Soliman and Spooner, 2000).

Another implication of this study is that investments in knowledge management strategy should be both inward and outward looking. Massive investments in knowledge management strategy that lacks a broad focus will be futile in achieving the desired goals. Such investments should be able to exploit the benefits of the external environment and the same time protect the firm from the risks the external environment poses. Therefore investments should cover the broad spectrum that defines the knowledge management strategy viz; knowledge management conception, knowledge strategy objectives, knowledge storage tools, knowledge transfer and application tools, knowledge protection tools, knowledge management implementation support systems based on cultural principles and leadership and on human resources practises.

This study has validated the importance of knowledge management strategy in building up dynamic capabilities of banks in a dynamic environment. Lack of knowledge management strategy can rob a firm of its capability to cope with the ever changing environment that marks the banking industry. Knowledge is a strategic asset which when appropriately leveraged can confer an organization with competitive advantage. The continued unveiling of innovative financial products such the Equitel (a SIM technology inspired platform to reach the unbanked who have access to mobile phones) is a mark of a good knowledge management strategy.

The study found that the type of knowledge management strategy the banks had a strong association to reengineering, restructuring and innovation. This is knowledge is of fundamental importance to the banks. It means that the banks might have to consider sharpening the weaknesses in their knowledge management strategies. Two areas that most banks had weaknesses revolved around transfer and application of knowledge and cultural principles and leadership essential for implementing a knowledge management system thus strategy. Over $50 \%$ respondents in some elements of the two thematic areas afore mentioned provided a rating of 5 and below in the Likert scale showing their lack of conviction in the banks' endeavour.

On transfer and application of knowledge, banks need to embrace projects that are made up of individuals from different specialities and functions. This will enable the sharing of more knowledge amongst employees. They also need to set up groups of learning amongst employees while aiming to be organizations of learning. While it is acknowledged that bank's culture is based on secrecy, mechanisms need to be put in in place for employees to access organizational data bases and repositories within reason. This will facilitate the growth of the employees and thus enable them execute their duties in a more informed manner. 
On cultural principles and leadership, employees need to be given more latitude to experiment and put into practise their new found knowledge. The threshold for tolerance of mistakes should be raised so as employees can experiment freely. No new knowledge can be created without making mistakes.

\subsection{Conclusion}

In configuring the knowledge strategy, commercial banks were observed to have a wide understanding of the concept of knowledge management. Knowledge management as a collection of techniques and tools used for the coming up with new knowledge, sharing and use of knowledge in pursuit of a firm's goals and objectives drew strong concurrence amongst all elements in knowledge management conception. The understanding of the concept of knowledge was also extended to the use of information technologies whose application is fairly excellent amongst the banks. The study also found that knowledge strategy objectives played a crucial in the banks' operation. Knowledge strategy objectives played a key role in cost reduction, product/service quality improvement, innovation capacity improvement and customer service improvement. This is crucial since the macro objective of any firm is shareholders' wealth maximization. It is also important because the objectives of the knowledge management strategy are consistent with organizational change through innovation.

On knowledge management tools; storage and protection tools were found to be comprehensive amongst commercial banks with robust application. Few issues were however noted in transfer and application of knowledge as part of knowledge management tools. Most respondents felt that the banks could do more by setting up multi-disciplinary project teams to facilitate knowledge transfer and by creating some groups of learning. This would enable the creation of learning organization which is consistent with knowledge management strategy objective. On implementation support systems for knowledge management strategy; support based on human resource practises was found to be good. Implementation support systems based on cultural principles and leadership had some few issues. Respondents pointed to lack of opportunities for experimenting and to a lower threshold for mistakes tolerance.

On organizational change; reengineering and innovation practises were found to be the most common. Restructuring was reported to be between moderately low and moderately high. The most common form of organizational change encompassed a mix of radical and incremental changes amongst the respondents' banks.

\section{References}

Barney, J.B. (2001). Resource- based theories of competitive advantage: A ten year retrospective on the resource- based view. Journal of Management, Vol.27, 643- 650. http://dx.doi.org/10.1177/014920630102700602

Becket, A.J., Wainwright, C. E.R. and Bance, D. (2000). Knowledge management: strategy or software? Management Decision, Vol. 38(9), 601 - 606 http://dx.doi.org/10.1108/00251740010357221

Bierly, P. and Chakrabarti (1996). Generic knowledge strategies in the U.S pharmaceutical industry. Strategic Management Journal, Vol.17 (winter special issue), 123 - 135

Boone Jr, H.N. and Boone, D.A. (2012). Analysing Likert Data. Journal of Extension, Vol.50 (2). Retrieved from http://www.joe.org/joe/2012april/tt2.php

Central Bank of Kenya. (2014). Bank Supervision Annual Report,2014. Nairobi: Author.

Central Bank of Kenya. (2015). Performance and Developments in the Kenyan Banking Sector for the Quarter ended 30th September, 2015. Nairobi: Author.

Choi, B. and Lee, H. (2002). Knowledge management strategy and its link to knowledge creation process. Expert Systems with Application 23, 173- 189. http://dx.doi.org/10.1016/S0957-4174(02)00038-6

Conner, R. K. (1991). A historical comparison of resource based theory and five schools of thought within industrial organization economics: Do we have a new theory of the firm? Journal of Management, Vol 17(1), 121-154. http://dx.doi.org/10.1177/014920639101700109

Consultative Group to Assist the Poor(n.d.). Top 10 Things to Know About M Shwari. Retrieved from http://www.cgap.org/blog/top-10-things-know-about-m-shwari

Cooper, D. R. and Schindler, P. S. (2014). Business Research Methods (12thed.). New York: McGraw- Hill Irwin.

Cresswell, J. (1994). Research Design: Qualitative, Quantitative and Mixed Methods Approaches. Los Angeles: SAGE

Donate, M. J. and Canales J. I. (2012). A new approach to the concept of knowledge strategy. Journal of Knowledge Management,Vol. 16(1), 22 - 44. http://dx.doi.org/10.1108/13673271211198927

Freilings, J. (2004). A competence based theory of the firm. Management Revue, Vol.15, 27-52 
Gao, F., Li, M. and Clarke, S. (2008). Knowledge, management, and knowledge management in business operations. Journal of Knowledge Management, $\quad$ Vol. $12(2), \quad 3 \quad-\quad 17$. http://dx.doi.org/10.1108/13673270810859479

Githua, T. C. W. (2013) Knowledge management practices for selected non-profit organizations in the health sector - Nairobi County. Unpublished MBA Research Project, University of Nairobi.

Greiner. M. E., Böhmann, T. and Krcmar,H. (2007). A strategy for knowledge management. Journal of Knowledge Management, Vol. 11(6), 3 - 15. http://dx.doi.org/10.1108/13673270710832127

Hammer, M. and Champy, J. (1993).Re-engineering the Corporation - A Manifesto for Business Revolution. London: NicholasBrealy Publishing.

Hodgson, G. M. (1998). Evolutionary and competence-based theories of the firm. Journal of Economic Studies, Vol.25 (1), 25 - 56. http://dx.doi.org/10.1108/01443589810195606

Jones, G. R. (2004). Organization Theory, Design, and Change. New York: Addison-Wesley Publishing Company. http://dx.doi.org/10.1108/09534810410538333

Joseph, M. and Stone G. (2003). Service quality in the banking sector: the impact of technology on service delivery. International Journal of Bank Marketing, Vol. 17, 182-91.. http://dx.doi.org/10.1108/02652329910278879

Kraska - Miller, M. (2008). Non Parametric Statistics for Social and Behavioural Science [ebrary Reader version]. Retrieved from ebrary database.

Kumar, S. (2013). Corporate restructuring in India with special reference to reliance industries Limited (RIL), Indian Journal of Research, Vol.3, 2250-2291

Knott, P. (2009). Integrating resource-based theory in a practice-relevant form. Journal of Strategy and Management, Vol. 2(2), 163-174. http://dx.doi.org/10.1108/17554250910965317

Malhotra, Y. (Ed). (2000). Knowledge management and virtual organizations. Hershey, USA: Idea group publisher. http://dx.doi.org/10.4018/978-1-87828-973-5

Maseki, C. (2012).Knowledge management and performance of commercial banks in Kenya. Unpublished MBA Research Project, University of Nairobi.

Massingham, P. (2014). An evaluation of knowledge management tools: Part 1 - managing knowledge resources. Journal of Knowledge Management, Vol. 18(6), 1075 - 1100. http://dx.doi.org/10.1108/JKM-11-20130449

Massingham, P. (2014). An evaluation of knowledge management tools: Part 2 - managing knowledge flows and enablers. Journal of Knowledge Management, Vol. 18(6), 1101 - 1126. http://dx.doi.org/10.1108/JKM11-2013-0449

Mugenda, O. M., \&Mugenda, A. G. (2003). Research methods: Quantitative and qualitative approaches. Nairobi, Kenya: Act press.

Muthee, K. M. (2014) Knowledge management as a strategic tool for competitive advantage at Safaricom Limited Kenya. Unpublished MBA Research Project, University of Nairobi.

Oluikpe, P. (2012). Developing a corporate knowledge management strategy. Journal of Knowledge Management, Vol. 16(6), 862 - 878. http://dx.doi.org/10.1108/13673271211276164

Ordinal Regression (n.d.). Retrieved from http://www.norusis.com/pdf/ASPC_v13.pdf

Pettigrew, A. M., Woodman, R. W. and Cameron, K. S. (2001). Studying organizational change and development: Challenges for future research. Academy of Management Journal, Vol. 44(4), 697 - 713. http://dx.doi.org/10.2307/3069411

Ritala, P. (2013). Linking the unlinked: knowledge-based perspective on non-routine change. Management Decision, Vol. 51(6), 1176 - 1189. http://dx.doi.org/10.1108/MD-11-2011-0418

Scalzo, N.J. (2006). Memory loss? Corporate knowledge and radical change. Journal of Business Strategy, Vol. 27(4), 60 - 69. http://dx.doi.org/10.1108/02756660610677137

Spender J.C. (2003). Exploring uncertainty and emotion in the knowledge-based theory of the firm. Information Technology \& People, Vol. 16(3), 266 - 288. http://dx.doi.org/10.1108/09593840310489386

Stennet, B. (2002). Opinion Survey Rating Scale. Retrieved from Http://www.assesmetplus.com/articles/opinion_survey_rating_scales.htm.

Sullivan, G.M. and ArtinoJr, A. R. (2003). Analysing and Interpreting Data from Likert Type Scale. Journal of Graduate Medical Education, Vol. 5(4), 541 - 542. Retrieved from http://www.ncbi.nlm.nih.gov/pmc/articles/PMC3886444/

Sveiby, K.E. (2001).A knowledge-based theory of the firm to guide in strategy formulation. Journal of Intellectual Capital, Vol. 2(4), 344 - 358. http://dx.doi.org/10.1108/14691930110409651

Tzortzaki, A.M. and Mihiotis, A. (2014). A review of knowledge management theory and future directions. Knowledge and Process Management, Vol. 21(1), 29 - 41. http://dx.doi.org/10.1002/kpm.1429

Van de Ven, A. H., and Poole, M. S. (1995). Explaining development and change in organizations. Academy of Management Review, Vol.20, 510-540. http://dx.doi.org/10.2307/258786

Wernerfelt, B. (1989). From critical resources to corporate strategy. Journal of General Management, Vol. 14, No 3 Spring 
Wernerfelt, B. (1995). The resource based view of the firm: Ten years after. Strategic Management Journal, Vol. 16(3), 171 -174. http://dx.doi.org/10.1002/smj.4250160303

Yang, R. S., Zhuo, X. Z., and Yu, H. Y. (2009). Organization theory and management: cases, measurements, and industrial applications. Taipei:Yeh-Yeh. 